\title{
Material Perforation
}

National Cancer Institute

\section{Source}

National Cancer Institute. Material Perforation. NCI Thesaurus. Code C62967.

Material constituting device is perforated possibly compromising the device's intended purpose. 